\title{
EU, NÓS E A INSTITUIÇÃO: FORMAÇÕES IMAGINÁRIAS SOBRE A AULA*
}

\author{
Eliane Maria Cabral Beck ${ }^{\star \star}$ \\ União de Ensino Superior do Paraná \\ Faculdade de Ciência e Tecnologia \\ Palotina, PR, Brasil
}

\begin{abstract}
Resumo: Este artigo discute as formações imaginárias relativas a manifestações discursivas de docentes, gravadas em aulas em uma instituição de ensino superior privada. Alguns questionamentos nortearam a investigação: como o professor imagina sua aula e de onde vem esse imaginário; o que ele ensina para além dos conhecimentos sistematizados; e como a relação professor/aluno via discurso ocorre em sala de aula. $O$ corpus é constituído de recortes de cinco aulas gravadas no curso de Administração, de cinco professores com formação em diferentes áreas. O referencial teórico é a Análise do Discurso de Linha Francesa. Como resultado, o texto constatou que, no momento em que o professor verbaliza, ocorre a incompletude, a falha, pois o conhecimento que possui está imbricado com o simbólico. Também verificou que a aula é mais do que uma prática de transmissão de conhecimentos científicos, pois o professor, determinado pelo imaginário constituído socialmente, reproduz valores, papéis e modos de pensar socialmente cristalizados.
\end{abstract}

Palavras-chave: Formações imaginárias. Aula. Professor.

\section{INTRODUÇÃO}

Ao analisar as aulas proferidas por professores de uma instituição de ensino superior privada, observou-se que a transmissão dos conhecimentos chamados científicos, na grande maioria das vezes, ocorre por meio de aulas expositivas. Prevalece, portanto, o método tradicional, em que o professor se posta em frente aos alunos e expõe os conteúdos, por meio de aula expositiva, método este utilizado no processo de ensino/aprendizagem, não só no ensino superior, como também no ensino médio e nas séries mais avançadas do ensino fundamental. Essa utilização da exposição oral deve-se, segundo Gil (2007), a fatores como a economia, a flexibilidade, a versatilidade, a rapidez e a ênfase no conteúdo.

$\mathrm{Na}$ maioria das vezes, "o intenso uso da exposição oral deve-se muito mais a circunstâncias de natureza administrativa, por ser uma estratégia econômica, flexível, rápida e que pode ser aplicada mesmo por quem não detenha muitos conhecimentos pedagógicos." (GIL, 2007, p. 138). Há, também, a ideia de que a aula expositiva facilita a apresentação organizada do conteúdo, permite a comunicação e é útil para a

\footnotetext{
* Este texto é parte da tese de Doutorado em Letras apresentada na Universidade Estadual do Oeste do Paraná - Unioeste, sob orientação do professor Dr. João Carlos Cattelan.

** Doutora em Letras pelo Programa de Pós-Graduação em Letras, Campus de Cascavel. Coordenadora do Curso de Artes Visuais - Uespar/Facitec - Palotina-Pr. E-mail: eliane.c.b@uol.com.br
} 
apresentação de conteúdos que ainda não estão disponíveis nos livros. Percebe-se que tudo se organiza para que o conteúdo tenha um lugar de destaque, pois é para isto que o professor é contratado: transmitir os conteúdos de determinadas disciplinas que fazem parte de um curso que tem como objetivo certificar os acadêmicos para uma determinada profissão, neste caso, formar administradores de empresas.

A exposição de conteúdos em sala de aula está sujeita, portanto, ao uso de uma língua, submetida a uma ideologia e condicionada por visões de mundo. Ao entrar em sala de aula para trabalhar com ementas já determinadas, o professor não só transmite conteúdos, mas produz modos de pensar, veicula valores, enuncia palavras por trás de outras palavras. Os professores deixam transparecer, via discurso, não ditos, palavras sob palavras, valores, produzindo efeitos de sentido que permitem a continuidade e a repetição do sempre lá e do mesmo.

Palavras, expressões e sequências, ao serem retomadas pelo professor em situação de ensino, não têm os mesmos sentidos utilizados pelo cientista, pelo banqueiro, pelo matemático ou pelo engenheiro. Ao utilizá-las em situação de ensino, o professor trabalha com efeitos de sentido que escapam ao que os profere. Na posição de quem ensina, há palavras sob as palavras, misturando o científico e o não científico e o conceito e o senso comum. Há uma mescla entre quem enuncia e o professor e a pessoa que ocupa outra posição fora da instituição: não um e outro, mas o mesmo que, devido às restrições a que está submetido, cristaliza via discurso aquilo que não pode ser dito por meio dos desvios.

No discurso do professor em sala de aula, percebe-se que tudo já foi dito em outro lugar e em outro momento e ele reforça isso: "vocês já viram", "vocês já sabem”. Porém, ao retomar, em outra condição histórica, o dito de outra forma, com outro "valor", é um professor universitário numa instituição de ensino superior quem diz. Que outro valor é esse? As aulas são paráfrases de outras aulas, porém o professor se responsabiliza como dono do dizer; é ele quem diz e isso auxilia a cristalização de valores e crenças.

Se a aula é um momento em que o professor estabelece um diálogo com o aluno e o conhecimento é construído nessa relação, esses enunciados produzidos em sala têm uma base que é a língua. Como aponta Pêcheux (2010 [1969]), existe uma base linguística regida por leis internas sobre a qual se constituem os processos discursivos. A língua, assim, deve ser vista como em funcionamento e se deve, então, tornar operacional o léxico e as regras, sem cair no subjetivismo empírico. Deve-se, ainda, entender que, para o linguista, os efeitos de sentido não são subjetivos: eles passam por uma fase de análise linguística, mas esta deve ser deslinearizada, sem cair na tentativa de uma semântica universal.

Pêcheux e Fuchs (2010 [1975], p.175) fazem referência à enunciação, vista como processo que consiste em uma série de determinações sucessivas que têm como características colocar o dito e rejeitar o não dito. A enunciação equivale, pois, a colocar fronteiras entre o que é selecionado e tornado processo aos poucos e o que é rejeitado, porém com a ciência de que ela é dirigida pelo inconsciente, que conduz a escolha dos recursos, da sintaxe e da modalização, dentre outros.

Ao examinar como as aulas são ministradas, busca-se, na análise a seguir, perceber o que os professores dizem de si e da relação com os acadêmicos e como o conteúdo é trabalhado em sala. 
As aulas foram gravadas com a anuência dos professores. No entanto, não foram revelados os dias, nem quais e nem quando, para que não houvesse, por parte destes, uma alteração em sua prática, já que poderia haver um "controle" maior do discurso do professor em sala.

A perspectiva teórica da pesquisa em que se fundamenta o analista do discurso é de base interpretativa e o método é aquele próprio à $\mathrm{AD}$. Dessa forma, quando se embasa a pesquisa sob o enfoque interpretativo da $\mathrm{AD}$, parte-se da premissa maior de que se desenvolvem interpretações da vida social e do mundo sob uma perspectiva cultural e histórica. Uma pesquisa de cunho interpretativo sempre é adjetivada como sendo crítica, pois todo conhecimento é influenciado por relações de poder, que são de natureza social e estão historicamente constituídas, e os discursos não podem ser separados do campo dos valores e da ideologia.

Neste trabalho, os sujeitos são os professores de um curso de Administração de faculdade particular. A pesquisa realizada pode ser caracterizada como de campo, pois a pesquisadora, além de buscar as informações naquele espaço, é também professora da instituição. Os participantes, portanto, sujeitos professores, com formação advinda de áreas diferentes, e compõem um grupo que leciona em um curso específico.

A escolha dos termos instrumentos e procedimentos na pesquisa foram adotados a partir dos seguintes critérios: os instrumentos são vistos como meios de coleta do corpus, neste caso, entrevistas semiestruturadas e gravação de aulas na forma de áudio, que também foram objeto de investigação; os procedimentos são vistos como a análise das aulas gravadas, que não seguem um roteiro elaborado por meio de fichas, mas correspondem à teoria adotada: foi realizada a transcrição das aulas e recortadas as sequências discursivas na forma de segmentação do corpus baseada na unidade temática definida para a investigação proposta.

O corpus foi coletado por meio da análise das respostas produzidas pelos professores nas entrevistas e dos enunciados produzidos em sala de aula por cinco professores pertencentes à instituição.

Nesse sentido, a pesquisa teve um caráter qualitativo-interpretativista, com o intuito de desenvolver o que Orlandi (2015, p. 61) denomina como "exausitividade vertical", que considera os objetivos da análise e a temática, ou seja, a análise dos enunciados produzidos em sala, para compreender se uma aula tende à transmissão de conhecimentos científicos, que apenas informa, ou se o professor está preso ao imaginário ilusório de uma aula e o que se tem é a reprodução de valores que se cristalizam socialmente.

A análise desenvolvida, portanto, baseia-se em enunciados resultantes das entrevistas e das gravações de sala de aula. O conjunto é formado por cinco professores, com diferentes áreas de conhecimento, que ministram aulas em um curso de Administração. Eles são designados de 1 (um) a 5 (cinco), para mantê-los anônimos. A professora 1 (um) trabalha com Matemática Financeira; o professor 2 (dois) com Metodologia Científica; o professor 3 (três) com Filosofia; o professor 4 (quatro) com Fundamentos da Economia, e o professor 5 (cinco) com Estatística Aplicada à Administração. 
A realização da pesquisa ocorreu pelo fato de a pesquisadora ser professora do curso e por ter realizado uma pesquisa anterior em parceria com a coordenação do curso, que tinha como preocupação verificar a metodologia utilizada pelos professores. Durante as discussões que ocorriam entre os colegas, havia, por parte da maioria dos professores, uma avaliação positiva de suas aulas, com declarações de que as aulas eram dialogadas, por meio de uma relação de troca. Por outro lado, havia um discurso repetido de que, apesar de explicarem muito o conteúdo e de repetirem a mesma coisa, os alunos não aprendiam, com expressões como "você fala, fala e eles não aprendem", ou "repeti várias vezes e foram mal na prova".

Ao realizar a análise e, portanto, atribuir sentidos, evidenciam-se situações que ocorrem em um espaço em particular, mas que podem auxiliar a compreender a prática do professor em sala de aula. A interpretação desenvolvida é, no limite, uma possibilidade dentre tantas outras.

\section{A AULA: A POSIÇÃO ASSUMIDA PELOS PROFESSORES}

Ao transcrever recortes das aulas ministradas, percebe-se que o lugar central do processo pertence ao professor; raras vezes, ao longo das gravações, há a voz dos acadêmicos. Ouvem-se apenas murmúrios ou conversas entre eles, e que parecem não se relacionar com o conteúdo trabalhado. Assim, a aula, imaginariamente entendida como um momento de troca e de diálogo, não se confirma nas gravações analisadas, já que se ouve apenas a voz do professor. Apesar de, nos enunciados recortados e apresentados a seguir, a aula se assemelhar a um momento de diálogo, de troca e de tentativa de construção conjunta, é o professor que fala. As aulas são, comumente, expositivas, sendo seguidas de exercícios de fixação.

As sequências discursivas a seguir foram recortadas de um corpus mais amplo (72 SDs), aqui numeradas de 1 a 13, e demonstram como ocorre a condução das atividades pelos professores, já se podendo afirmar que cabe a eles a iniciativa:

\footnotetext{
SD 01 Pessoal, vamos fazer a correção? (Professor 1) Então vamos lá. (Professor 2) Vamos ver se vocês entenderam, certo? (Professor 3) Então vamos continuar? (Professor 4) [...] vamos começar a trabalhar com o exercício propriamente... (Professor 5).
}

O exame desse recorte discursivo indica que é o professor que dirige os alunos, referentes específicos de um espaço que é a sala de aula. Ao utilizar a primeira pessoa do plural, num sentido coletivo, ele simula socializar o dizer, como quem se coloca na mesma posição de aprendiz, ficando, assim, a posição de autoridade neutralizada. Os verbos na primeira pessoa do plural buscam caracterizar um trabalho coletivo, como se fosse nós: eu, professor, e vocês, alunos. Indursky (2013), em seus estudos, avalia o nós como uma não pessoa discursiva, que corresponde ao referente não especificado ao qual o eu se associa para constituir nós. Assim, simula-se uma simetria entre professor e aluno como em situação de iguais e como se não houvesse posições distintas. Mariani (2001) referese ao "nós" como a projeção de uma imagem de coletividade, como se, ao utilizar-se do "nós", houvesse um reforço do grupo como homogêneo e coeso. 
Ao utilizar "vamos", a posição assumida pelos professores, de forma geral, é a daquele que faz parte do grupo, como se não houvesse professor e alunos. Com "Nós vamos", o professor simula uma simetria entre ele e os alunos, criando a imagem de um espaço de igualdade, pois o eu pessoal se ausenta da enunciação. O uso desse recurso tem, muitas vezes, o objetivo de influenciar o interlocutor, no caso, o aluno, para que realize a ação sugerida evitando polêmicas e desafios.

Mas há momentos em que o docente usa a primeira pessoa do singular:

SD 02 Sei que não ficou claro para vocês... (Professor 1) Eu sei que tem gente precisando introduzir a fórmula na calculadora para que possa fazer o trabalho... (Professor 1) Vocês já leram o texto e eu não vou precisar fazer a leitura novamente, ok? (Professor 2) Eu vou resolver, então, contigo essa. (Professor 3) Se existem dúvidas e quiserem pedir eu vou tentar explicar, ok? ... (Professor 3) Eu quero que vocês desenvolvam certinho... (Professor 5).

O lugar reassumido pelos professores muda e o "eu" que fala reforça o poder e a autoridade que tem, como se todo o saber fosse daquele que fala, e apresenta o que diz como incontestável (eu sei, portanto, é verdade). Na voz do professor, há a voz da experiência daquele que detém o conhecimento; logo, ele ensina e assume o papel de quem está ali para ensinar. Desse modo, o professor se divide entre um "eu", quando se refere ao trabalho do professor (esclarecer, explicar uma fórmula, resolver, explicar e desenvolver um exercício certo) e um "nós", quando se refere ao trabalho dos alunos. De acordo com Barthes (2004), ocorre, neste caso, o conforto da relação docente: o bom professor e o bom aluno são aqueles que aceitam filosoficamente o plural de suas determinações e o vivem adequadamente.

No entanto, essa não é uma constante. Em alguns momentos, o eu não se refere àquele que diz $e u$, mas, segundo Indursky (2013), aparece como se houvesse a opacificação do sujeito professor como se ele estivesse separado do discurso que enuncia; ao mesmo tempo, o uso da primeira pessoa parece indicar um sujeito interpelado pelo saber institucionalizado em que se encontra o saber e o poder. E isto ocorre não só nos chamados para as atividades, mas também quando acontece a exposição dos conteúdos trabalhados:

SD 03 ...quando eu falava no balanço... eu quero que você fale a fórmula de juro simples e essa fórmula, mas se eu quiser calcular a taxa... é a mesma fórmula... porém eu quero conhecer a taxa, eu vou a taxa é igual ao valor de juro dividido pelo capital multiplicado pelo período eu vou conhecer a taxa de juros e se eu quiser o tempo eu inverto a fórmula, eu vou pegar juro eu vou dividir pelo resultado do capital multiplicado pela taxa... (Professor 1).

Como se pode notar, a professora reflete sobre a fórmula como se ela fosse parte do problema apresentado e como se fosse ela a autora do que diz: "se eu quiser... eu inverto". Com isso, cria um efeito ilusório de subjetividade, passando a imagem de quem tem o poder de mudar ou de alterar o que quiser.

SD 04 Transformando: 0 é igual a 1 mais o período que eu tenho, elevado ao período que eu quero, dividido pelo período que eu tenho menos um. Eu quero o inicial, então isto é igual a um mais, qual é a taxa que eu tenho? Qual é a taxa que eu tenho? Qual é o período que eu 
quero descobrir a taxa? Eu quero descobrir a taxa de um mesmo. Qual é o período que eu tenho? Eu tenho uma taxa, essa taxa que é variável a esse valor aqui, então o período aqui está sempre vinculado a essa taxa aqui. Então eu tenho, atualmente, uma taxa anual e eu quero descobrir uma taxa mensal. Então, um sobre uma, mas como eu falo em dinheiro, eu devo falar em dinheiro, eu devo falar a mesma linguagem, então, um dividido por doze. (Professor 4).

"Eu tenho", "eu quero" e "eu devo", apesar de linguisticamente criarem este efeito, obviamente não se referem ao professor, mas permitem criar um efeito de simulação de alguém que tem, que quer e que deve algo, como se isso pertencesse a uma decisão pessoal e subjetiva. Assim, ao falar de taxas e valores o professor, utilizando "eu", simula, sem o saber, uma aproximação com aquilo que diz e também com aquele que ouve.

\begin{abstract}
SD 05 Se eu chegar, tô devendo um título, uma nota promissória, uma nota promissória de mil reais, eu chegasse com dinheiro, pagasse, desse mil reais pra ela, ela me devolve a nota promissória, eu me liberei da dívida? Estou liberado da dívida? Tenho algum compromisso ainda? Não, eu estou liberado. (Professor 4).
\end{abstract}

A exemplificação dada pelo professor simula que todos devem e pagam dívidas, inclusive o "eu" que fala, incutindo a obrigação de, no caso de contrair dívidas, pagá-las. Ele está, portanto, pautado num imaginário que se apoia num “conhecimento teórico" que aparece exemplificado e concretizado pela aproximação com o mundo do capitalismo e com a obrigação de atender a seus ditames, como em "eu me liberei", "estou liberado".

Balanços, taxas, capital, fórmulas, promissórias e dívidas vão sendo falados pelo professor: "eu vou pagar juro", "a taxa que eu tenho", "eu me liberei da dívida", como se ele ocupasse esses lugares enunciados e permitisse que os alunos se identificassem com ele ou com o que está "ensinando". No limite, nos três casos o "eu" não remete ao professor, mas é o "eu" do discurso da matemática, ou outro. A instituição fala nele; ele é o suporte. Eis a ilusão por parte do professor, que se vê como figura central do discurso quando é apenas seu porta-voz. Pêcheux e Fuchs (2010 [1975], p.175) afirmam, em relação ao sujeito, que ele não é uma entidade, mas uma posição dada pela linguagem, que não é a dupla face do sujeito, mas exterior a ele; o sujeito não é mais do que uma posição, dada pelo sempre-já-lá da linguagem. Neste sentido, Pêcheux (2010 [1983]) se coloca entre o sujeito da linguagem (eu digo eu) e o sujeito da ideologia (quem é este eu): no limite, o confronto ocorre entre a evidência subjetiva da língua e a evidência de interpelação pela ideologia que coloca o discurso entre a linguagem e a história. Para Pêcheux e Fuchs (2010 [1975]), abre-se, então, a possibilidade de estabelecer a articulação entre o sujeito que se crê fonte de seu discurso e aquele que é tão somente interpelado.

O efeito de sentido produzido é que, linguisticamente, o "eu" é sempre o mesmo, mas a posição adotada é diferente em cada uso, delimitando o lugar que ocupa o sujeito que ensina e o que aprende. É a linguagem que estabelece esses ditames e não o sujeito, já que não há como escapar dessa armadilha, segundo Barthes (2007, p. 14), porque "a língua é mesmo fascista". Ainda, segundo Barthes (2004), o professor, ao falar para e diante de alguém que não fala, é aquele que diz "eu" e pouco importam os subterfúgios de "a gente", do "nós" ou da frase impessoal. Ele expõe um saber e propõe um discurso, 
que não sabe como será recebido, pois não há garantia de imagem definitiva. Em regra, não é o saber que é exposto, é o sujeito que se expõe com um discurso que é atravessado, disjunto e laminado.

Assim, a aula se constrói nesse jogo entre um "eu" e um "nós”, que vai demarcando a posição de cada um, com um distanciamento do professor em relação ao aluno, mesmo quando ele utiliza "nós", pois isso ocorre no momento em que o aluno precisa realizar as atividades e isto revela uma atitude imperativa. Poder-se-ia, neste caso, pensar no que Huizinga (2014) fala sobre o "jogo". Para ele, o jogo tem seus domínios próprios, principalmente na religião, no direito e na ética. E, num jogo, ganhar indica a superioridade do vencedor, que ganha mais do que o jogo: ganha estima e conquista honrarias. Mas, mais do que isso, demonstra ser melhor do que os outros.

Para o autor, sempre houve uma relação de poder entre aqueles que têm o conhecimento e os que não têm: o filósofo desafiava seus rivais, submetia-os à crítica, afirmava suas opiniões como verdadeiras, falava invariavelmente na primeira pessoa e fazia o jogo da pergunta e resposta para exibir seus conhecimentos. Os homens, nas disputas diárias, estabelecem seus jogos, que servem para disputar espaços físicos e confirmar espaços existenciais, o que ocorre a partir da força ou pela palavra, pela imposição ou a partir de uma aula, neste caso.

"Sem" imposição e por meio de uma relação relativamente estável, os professores assumem a posição de detentores do conhecimento, que é reforçada por meio de expressões como 'explicar', 'aprender', 'ensinar' e demonstram que a sua fala nem sempre é apreendida por todos, destacando que o papel do professor é estar ali para ensinar, papel que lhe foi conferido por uma instituição da qual faz parte. Isto tudo corrobora a afirmação de Pêcheux (2010 [1969], p. 81) de que não se deve entender o discurso como simples transmissão de informação, mas como efeito de sentido entre A e B, os quais designam lugares determinados na estrutura de uma formação social, a partir das formações imaginárias que designam os seus lugares e como estes se veem e veem o lugar do outro. Na relação em sala, o professor e o aluno ocupam os lugares que a instituição impõe, colocando a um hierarquicamente superior ao outro, mesmo quando a relação parece se tornar simétrica.

SD 06 Já falei, mas vou repetir... (Professor 1) [...] vocês aprenderam lá na matemática financeira vocês darão sequência agora. (Professor 1) Vou explicar rapidamente... Vocês já aprenderam isso lá no Ensino Médio... (Professor 2) Isso é para vocês aprenderem o que é uma pesquisa de campo... (Professor 4) Isso que eu tô querendo ensina pra vocês. (Professor 5) Vamos ver se vocês entenderam, certo? Pessoal, o que eu quero dizer de fato..., que vocês entendam como é feito o trabalho, se vocês entenderem como que faz o projeto vocês não vão ter dificuldade nenhuma no TCC (Professor 5) Conseguiram entender qual é o objetivo do nosso trabalho? (Professor 5).

Nos enunciados acima nota-se que, na relação estabelecida em sala de aula, é constante, por parte dos professores, a verificação, se houve compreensão, entendimento e aprendizagem. Essa necessidade passa pela visão de que algo que é "ensinado" precisa ser aprendido imediatamente pelo outro, como se conhecer, aprender e entender fossem ações que ocorressem na relação entre o dizer e o receber imediato: o sujeito professor 
expõe e o sujeito aluno aprende. O professor vive o imaginário de que, ao "transmitir" o conhecimento a alguém, por meio da linguagem, este é imediatamente apreendido, o que materializa a visão humanista que prega a centralização do conhecimento na figura do professor, que transmite informações que devem ser apreendidas como verdades. O que entenderam ou como entenderam são problemas que não podem ser respondidos, pois a organização do modelo de ensino que se tem é o de uma sala com vários alunos e um professor que ensina a partir do repasse de conteúdos definidos pela instituição a partir de uma ementa já pronta, em geral copiada de outros lugares.

O professor, vivendo a aula como uma ilusão no modo do "como se", utiliza enunciados como "vamos ver se vocês entenderam" ou "vocês conseguiram entender", como se o conhecimento pudesse ser percebido e assimilado apenas a partir de um exercício resolvido ou uma resposta bem elaborada.

Mesmo que esse espaço seja conhecido e institucionalizado e mesmo sabendo que não há como verificar se o que foi dito foi apreendido da maneira que o professor espera, a ilusão da transparência da linguagem e do sentido surge como um ato falho que impulsiona (digo e explico, logo todos deveriam aprender) os questionamentos do docente após a explicação dos conteúdos que, em muitos momentos, são enfáticos:

SD 07 Vocês não entenderam? Você não entenderam a divisão dos ativos financeiros? (Professor 4) Entenderam? Entenderam? (Professor 5).

Nos enunciados acima, a presença da negação no questionamento do professor 4 permite uma leitura diferente da do professor 5. Quando o primeiro questiona da forma como fez, é possível perceber o não dito ${ }^{1}$, a indireta ou o implícito, que não pode vir à tona e nem ser dito explicitamente. Há, portanto, uma insinuação, que não pode ser dita, pois pode se transformar em uma ofensa ou uma agressão verbal. Na posição que o professor ocupa, ele só pode dizer de forma indireta. Além disso, esse é o papel do professor: ele deve ensinar e, se os alunos não aprenderam, há um contradiscurso, que pesa sobre o docente: o da instituição e dos próprios alunos de que foi incompetência sua a não aprendizagem.

Por outro lado, o não dito pode vir marcado por meio de perguntas de cunho irônico. Ao se dirigir aos seus interlocutores, o professor 4 pergunta, responde e faz uma apreciação que pode ser compreendida de duas formas: a primeira, que há uma compreensão por parte do grupo sobre o assunto apresentado, e isso é "ótimo"; a segunda, que o grupo não faz perguntas, pois não compreendeu o assunto e há, no caso, uma ironia presente na expressão "ótimo", que equivale, mais ou menos, a: "ainda bem, não preciso repetir".

SD 08 Alguma dúvida? Não? Ótimo! (Professor 4).

\footnotetext{
${ }^{1}$ Não entenderam, são ignorantes? Como não entenderam?
} 
Novamente, percebe-se a aula como um espaço de jogo entre o que é dito e o que é compreendido ou não pelos alunos. São relações conturbadas de demarcação de espaço, pois o professor "sabe" que não pode dizer tudo o que pensa e o aluno "sabe" que não pode retrucar gratuita e descuidadamente, pois precisa respeitar o professor, afinal depende também disso para ter uma boa nota e seguir a vida acadêmica. Estes são sentidos que permeiam o espaço escolar, mas que não são revelados, pois isso não é assunto para discutir. Há uma espécie de contrato imaginário, conforme Barthes (2004), que não é quebrado, já que o professor está ali para honrar seu emprego e o aluno para buscar uma carreira. O professor espera que o aluno o reconheça como cumpridor do seu papel, pois ele detém autoridade, é benevolente, não pode ser contestado, ele sabe, etc. e o aluno imagina que esteja sendo conduzido para uma boa carreira profissional.

Em outros momentos, os questionamentos feitos pelos professores, de forma repetitiva e constante, ora por meio de perguntas retóricas, ora pela necessidade de manter o diálogo com a turma, reforçam a posição ocupada por cada um dos sujeitos na relação em sala de aula. É o professor que, unilateralmente, questiona os alunos, e isso deve ser aceito e não pode ser discutido, ou negociado, como indicam os enunciados a seguir:

SD 09 O dinheiro tem grau de liquidez absoluta e o cheque tem grau de liquidez relativa. Por quê? (Não há respostas por parte dos alunos) Por quê? (Eu pergunto, diz um aluno) Perguntei primeiro, diz o professor. (PROFESSOR 4).

A relação estabelecida entre quem tem o saber e quem supostamente não tem, como se vê, é constantemente mantida no processo de perguntas que os professores fazem, mesmo que, aparentemente ${ }^{2}$, às vezes, pareça haver uma relação de diálogo:

\begin{abstract}
SD 10 Posso seguir? (Professor 1) Dúvidas? Não dúvidas? (Professor 1) Tudo bem? Vocês preferem que eu atribua letras ou números? (Professor 1) Sabem por quê? (Professor 2) Estão lembrados? (Professor 3) Vocês entendem o que seria? (Professor 4) Alguma dúvida mais pra responder? Não? (Professor 4)
\end{abstract}

$\mathrm{Na}$ fala do professor 3, ao longo das SDs, a incidência de perguntas é constante e as interrogativas procuram fazer com que o interlocutor se comprometa com o assunto discutido. No entanto, não há resposta por parte dos alunos; o próprio professor vai respondendo suas perguntas e, dessa maneira, tem a sensação de que a ação desejada é orientada, como no caso em que ele sugere aos alunos que anotem as partes que "eles" consideram mais importantes, mas ele próprio reforça o que considera essencial.

Parece que, ao agir assim, "dialogando", "perguntando", os professores produzem um efeito de que em suas aulas há uma participação efetiva por parte dos alunos e que há uma troca de experiências; porém, na prática, eles não permitem, em nenhum dos momentos analisados, que os alunos intervenham ou sejam estimulados a participar de fato. Bourdieu e Passeron (2012) dizem que o professor pode convocar a participação ou a objeção dos alunos, sem jamais correr o risco de que realmente se instaurem, pois as interrogações são apenas interrogações oratórias ou retóricas, com o objetivo apenas de confirmações.

\footnotetext{
${ }^{2}$ Nas aulas gravadas, não há respostas por parte dos acadêmicos.
} 
É o professor quem fala de forma ininterrupta:

\begin{abstract}
SD 11 Vocês leram o texto em casa? Não? Então vamos ler aqui. Então, na quinta-feira, nós vamos fazer uma leitura rápida e vocês vão, com uma caneta marca-texto, sublinhando, anotando os principais tópicos do texto, até o seu final. - Na quinta-feira. Na outra terça-feira, nós vamos retomar, sem o texto, aliás, vocês vão ficar com a mesma nota, mas nós vamos sinalizar e apontar, no quadro, os principais tópicos, que vocês leram, que vocês apontaram como mais importante, concorda? Porque é melhor assim? Porque aí eu respeito o ritmo de cada um, não é verdade? O que nós vamos fazer agora, no círculo de leitura aqui, nós não vamos respeitar o ritmo de cada um, vamos ter que ir lendo, debatendo e coisa e tal. Vamos ter que ler, debater, coisa e tal, observar o quadrado, está certo? Na próxima aula, nós vamos sair um pouquinho do texto, vamos ter um debate, um pouco melhorado. Vocês já leram o texto e eu não vou precisar fazer a leitura novamente, ok? (PROFESSOR 3).
\end{abstract}

Há momentos em que ocorre a presença de verbos injuntivos, como "ter que ler", "vamos fazer", "vamos ter", que revela um discurso com poder que não permite aos interlocutores uma atitude contrária à "sugerida". Para Bourdieu e Passeron (2012), a linguagem do magistério é uma das mais eficazes e sutis para conseguir o distanciamento de que a instituição dota seus agentes. Ao falar, o professor carrega o poder concedido pela instituição e, por mais que procure se distanciar de uma figura tradicional (estrado, toga e centralização) ele faz sempre o uso professoral de uma língua professoral.

Ao final, o professor 3 reforça o discurso a partir de uma pergunta, o que não deixa nenhuma dúvida sobre o que está propondo/impondo. Há um discurso de tom aparentemente conciliatório e de aproximação entre professor e aluno, em que se observa uma reiteração de acordos estabelecidos, porém vê-se que se sobrepõe a voz daquele que pode dizer: "vão sim, terão":

SD 12 Vão sim. Na quinta-feira. Porque hoje vocês ainda terão que ir atrás desse material, nós vamos fazer uma leitura conjunta, então, e quinta-feira vocês vão fazer isso aqui, porque eu havia prometido pra vocês, lá na primeira série, que nós não faríamos trabalho em casa, lembra? Tá lembrado? (Professor 3).

No trecho abaixo, ocorre a presença do verbo no imperativo e, por meio da pergunta feita, o professor procura conduzir, a partir da referência a uma aluna, a direção de uma determinada perspectiva sobre o assunto. Apesar do objetivo de estimular a aluna a entrar na discussão, atribuindo-lhe o papel de interlocutora crítica, não há sucesso no intento e é o professor que responde:

SD 13 - Leia então. - Espera um pouquinho aí. Só um pouquinho aí. C.., o que você entendeu destas duas frases que a, que, que a E... leu? - Nada. - Ah, tá bom. Sabe por quê? Porque aí nós estamos mexendo num objeto, num campo antropológico muito sério que nós vamos a partir de..., tá certo? (Professor 3).

De forma geral, pode-se dizer que a aula vai sendo construída por meio dessa relação de perguntas (na maioria das vezes sem) e respostas, o que consolida uma prática que vai se instaurando de forma silenciosa, pois há sentidos que não são discutidos, vazios que não são preenchidos e isso acaba sendo manifestado nas atitudes das pessoas e nas práticas sociais. 
Percebe-se que os questionamentos, em sua maioria, não provocam o outro no sentido de buscar respostas, de justificar e de argumentar, ficando no teste dos conhecimentos e no apoio ao que diz o professor. A interação, como efetiva participação, mesmo quando ocorre o uso do "nós" ou do "eu" ou da instituição simulada num "eu" científico, ocorre pela fala de um e pelo silenciamento do outro num "movimento" claramente monofônico, homogêneo e centralizador.

Imaginariamente, porém, o professor é aquele que dirige o espetáculo, além de ser o mediador, o motivador e o transmissor de conteúdos. No entanto, nas aulas gravadas e analisadas, os professores trabalhavam os conteúdos que estavam previstos nas ementas e assumiam o lugar de detentores do saber e os alunos eram aqueles que estavam ali para aprender.

O que se percebe é que o professor se tornou alguém que tem o papel de controle do tempo, da postura e dos comportamentos dos alunos durante a relação com o conhecimento. A instrução ocorre por meio do que sinalizam as ementas e compete ao professor distribuir o tempo e os grupos e verificar se houve "fixação" do conteúdo (GERALDI, 2010), que é repassado como se fosse "natural", simulando algo como "é assim que as coisas são": a "ciência socializada e imóvel” (BACHELARD, 1996, p. 30). $\mathrm{O}$ professor, diante do que lhe permite a instituição, repete o que já está posto como regra: aulas de tantos minutos, provas por bimestres, livros de chamada e conteúdos por série/ano.

Porém, mesmo sendo interpelados pelo processo imaginário do que são professor, aluno e conteúdo, os docentes "esquecem" as condições em que estão inseridos e defendem, muitas vezes, a "percepção" de que os alunos não aprendem porque não querem, porque não estudaram, porque não quiseram aprender e, por isso, eles são "culpados" por sua ineficiência, pois eles, professores, cumpriram o seu papel: ensinaram, participaram ativamente e contribuíram para a aprendizagem dos alunos, sem se dar conta do mascaramento imposto sobre o "real" do papel que o professor desempenha e que é ditado pela instituição.

\section{REFERÊNCIAS}

BACHELARD, G. A formação do espírito científico: contribuição para uma psicanálise do conhecimento. Trad. Estela dos Santos Abreu. Rio de Janeiro: Contraponto,1996.

BARTHES, R. O rumor da língua. São Paulo: Martins Fontes, 2004. Aula: aula inaugural da cadeira de semiologia literária do Colégio de França. Trad. Leyla Perrone. São Paulo: Cultrix, 2007.

BOURDIEU, P.; PASSERON, J.-C. A reprodução: elementos para uma teoria do sistema de ensino. Trad. Reynaldo Bairão. Petrópolis RJ: Vozes, 2012.

GERALDI, J. W. A aula como acontecimento. São Carlos: Pedro \& João Editores, 2010.

GIL, A. C. Didática do Ensino Superior. São Paulo: Atlas, 2007.

HUIZINGA, J. Homo ludens: o jogo como elemento da cultura. São Paulo: Perspectiva, 2014.

INDURSKY, F. A fala dos quartéis e as outras vozes. 2. ed. Campinas, SP: Editora Unicamp, 2013. 
MARIANI, B. Questões sobre a solidariedade. In: ORLANDI, E. P. (Org.). Cidade atravessada: os sentidos públicos no espaço urbano. Campinas, SP: Pontes, 2001. p. 43-50.

ORLANDI, E.P. Análise de discurso: princípios e procedimentos. 12. ed. Campinas, SP: Pontes, 2015. PÊCHEUX, M. Análise automática do discurso (AAD-69). In: GADET, F.; HAK, T. (Org.). Por uma análise automática do discurso: uma introdução à obra de Michel Pêcheux. Trad. Bethania S. Mariani. 4. ed. Campinas: Editora da Unicamp, 2010 [1969]. p. 59-158.

A análise de discurso: três épocas (1983). In: GADET, F.; HAK, T. (Org.). Por uma análise automática do discurso: uma introdução à obra de Michel Pêcheux. Trad. Bethania S. Mariani et al. 4. ed. Campinas: Editora da Unicamp, 2010 [1983]. p. 307-315.

PÊCHEUX, M.; FUCHS, C. A propósito da análise automática do discurso: atualização e perspectivas (1975). In: GADET, F.; HAK, T. (Org.). Por uma análise automática do discurso: uma introdução à obra de Michel Pêcheux. Trad. Bethania S. Mariani et al. 4. ed. Campinas, SP: Unicamp, 2010 [1975]. p. 159-249.

\section{Recebido em: 15/05/17. Aprovado em: 29/11/17.}

Title: Me, us, the institution: imaginary formations on the classroom

Author: Eliane Maria Cabral Beck

Abstract: This paper discusses the imaginary formations related to discursive manifestations of teachers, recorded in classes in a private higher education institution. Some questions guided the investigation: how the teacher imagines his class and where this imaginary comes from; what he teaches beyond systematized knowledge; and how the teacher / student relationship via speech occurs in the classroom. The corpus consists of five class cut-outs recorded in the Administration course, of five teachers from different areas. The theoretical reference is the French Discourse Analysis. The text found, as a result, that at the moment the teacher verbalizes, the incompleteness occurs, the failure, because the knowledge he possesses is imbricated with the symbolic. It also verified that the class is more than a practice of transmission of scientific knowledge, because the teacher, determined by the socially constituted imaginary, reproduces socially crystallized values, roles and ways of thinking.

Keywords: Imaginary formations. Class. Teacher.

Título: Yo, nosotros y la institución: formaciones imaginarias sobre la clase

Autora: Eliane Maria Cabral Beck

Resumen: Este artículo discute las formaciones imaginarias relativas a manifestaciones discursivas de docentes, registradas en audio en clases en una Institución de Enseñanza Superior privada. Algunos cuestionamientos nortearan la investigación: cómo el profesor imagina su case y de adonde viene ese imaginario; lo que él enseña allá más de los conocimientos sistematizados; y cómo la relación profesor/alumno vía discurso ocurre en clase. El corpus es constituido de recortes de cinco clases registrados en audio en el curso de Administración de cinco profesores con entrenamiento en diferentes áreas. El referencial teórico es el Análisis del Discurso de Línea Francesa. Como resultado, el texto ha constatado que en el momento en que el profesor habla ocurre la incompletud, la falta, pues el conocimiento que posee está imbricado con el simbólico. También ha verificado la clase es más que una práctica de transmisión de conocimientos científicos, pues el profesor, determinado por el imaginario constituido socialmente, reproduce valores, roles y modos de pensar socialmente cristalizados.

Palabras clave: Formaciones imaginarias. Clase. Profesor.

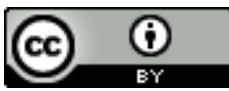

Este texto está licenciado com uma Licença Creative Commons Atribuição 4.0 Internacional. 